\title{
Research on New Type Think Tank Talent Support Innovation Management: Taking Pingxiang City of China as an Example
}

\author{
Jin Zheng ${ }^{1}$ Jinchun Huang ${ }^{2, *}$ Qiyan $\mathrm{Li}^{1}$
}

\author{
${ }^{1}$ School of Business, Macau University of Science and Technology, Macao, China \\ ${ }^{2}$ School of Business, Pingxiang University, Pingxiang, Jiangxi, China \\ *Corresponding author. Email: 49151752@qq.com
}

\begin{abstract}
China's economy is developing rapidly, and the construction of talent think tanks is an important support for economic development. This study takes Pingxiang City, China as an example, analyzes the current situation of Pingxiang think tank talent construction, summarizes the shortcomings of Pingxiang think tank construction, and combines existing urban construction projects in Pingxiang City to build a new type of think tank model suitable for the development and construction of Pingxiang City. Through the six aspects of management mechanism, talent management, development environment, excellence mechanism, working mechanism and public communication, this paper specifically explores the support and innovative management approaches of Pingxiang's new think tank talents, and finally proposes a reasonable improvement direction for the construction of new think tank talents in Pingxiang City as well as some constructive, actionable, and forward-looking recommendations.
\end{abstract}

Keywords: new type of think tank, talent support, think tank talent construction, urban innovation management, Pingxiang City

\section{INTRODUCTION}

China's economy is developing rapidly, and the demand for high-quality talents is growing. How to attract high-quality talents and how to use them reasonably has become a problem faced by governments across China. After the General Office of the Central Committee of the Communist Party of China and the General Office of the State Council of China jointly issued the "Opinions on Strengthening the Construction of New Type Think Tanks with Chinese Characteristics" in early 2015, all provinces and municipalities in China enthusiastically responded to the central call and actively participated in the construction of talent think tanks.

Pingxiang City is located in central China. Because of its abundant coal resources, the coal industry has developed rapidly and has achieved early capital accumulation. But now, the "golden decade" of the coal industry has long since passed. In the face of depletion of resources, Pingxiang must be transformed and upgraded, and the construction of a talent think tank is the basis for industrial transformation and upgrading.

*Fund: This research was funded by Social Science Research Project of Pingxiang of China (2018GL05).
This study will analyze the advantages and disadvantages of the construction of new think tanks in Pingxiang City from the perspective of innovation management of Pingxiang City, combined with the specific situation of economic and political development of Pingxiang City. To build a new think tank model that matches the political and economic development of Pingxiang. The six important indicators of management mechanism, talent management, social environment, excellence mechanism, working mechanism and public communication are analyzed to discuss the importance of the new think tank model for the construction of Pingxiang think tank. Combining corresponding indicators, a reasonable improvement direction and constructive, operable, and forwardlooking suggestions for the construction of new think tanks in Pingxiang City will help Pingxiang City to make more scientific and effective decisions and better urban innovation management.

\section{LITERATURE REVIEW}

\section{A. Think tank research}

Think tank research began in the western countries represented by the United States. In the European and 
American countries, think tank is a relatively independent research institution, and public policy is the research object of think tank. Its goal is to provide decision-making advisory services for the government, and then affect government decision-making. Because the research conducted by think tanks is not purely on a certain discipline or a specific field, the talent team of think tanks is generally composed of multi-disciplinary experts. Think tanks provide decision-making reports for decision-makers by using scientific research methods. The scholar Donald (2002) thinks think tanks are "institutions that create, reorganize and promote ideas for public policy makers and the public". The research on modern think tanks in China started late. Wu Tianyou and Fu Xi (1982) edited and published the first monograph on American think tanks in China, the important think tanks in the United States. After that, a series of scholars mostly introduced the development of think tanks in western countries. Jin Fang (2010) and other works western scholars on think tanks introduced western think tanks Comprehensive and in-depth systematic research is of reference significance to the construction of Chinese think tanks; Hu Angang (2014) proposed the significance and methods of building a new type of think tank with Chinese characteristics from the perspective of practice; Zhu Xufeng (2009) discussed the functions and internationalization of think tanks, and from the perspective of new research, he used the methods of investigation, research and case interview to comprehensively explore the Chinese and international think tanks Profound and systematic research, in the process of research, has obtained a large number of first-hand information, which provides a large number of facts and theoretical basis for the study of the think tank. Its research on China's internal and external policy processes and think tanks is of great significance for the construction of Chinese think tanks and an indispensable part of the work of building a new type of think tank with Chinese characteristics. Wang Lili (2012) introduced the "revolving door" mechanism of American think tanks, incorporated the research on American think tanks into the research framework of public opinion, put forward the theory of "public policy public opinion field", and clarified the United States Generation mechanism of influence of think tanks in China; Ren Xiao (2015) thinks think tanks are "nonprofit policy research institutions that conduct research on public affairs and provide solutions to the government and society"; think tank research center of Shanghai Academy of Social Sciences (2014) thinks think tanks are "institutions that conduct research, analysis and promotion of public policies and provide policy tendentiousness research on domestic and foreign affairs in China, analysis and suggestions to enable policy makers and the public to make clear judgments on public policy issues".

\section{B. Research on local think tanks}

As China attaches great importance to the development of new think tanks, think tanks are being built all over China. Think tanks have a profound impact on Contemporary China's politics, economy, culture, education and other aspects. A good think tank can help the government to make suggestions on various issues and improve the effectiveness, timeliness, scientificalness and preciseness of government decision-making by combining scientific research theories and practical methods. At present, some scholars in China have done relevant research on the construction of think tanks in various cities ("Table I"), but most of the research is only from a single point of view, and cannot describe the indicators needed for the construction of new think tanks. This study attempts to establish a new think tank model system in Pingxiang City, China, which can comprehensively describe the specific indicators of new think tank construction on the basis of previous scholars' research.

TABLE I. RESEARCH ON TALENT THINK TANKS IN DIFFERENT REGIONS OF CHINA

\begin{tabular}{|c|l|l|}
\hline Regional & \multicolumn{1}{|c|}{ Main Viewpoints } & \multicolumn{1}{|c|}{ Literature Sources } \\
\hline Jiangsu Province & Applies strategic management theory to think tank construction & $\begin{array}{l}\text { Xu Xiao-Hu (2014), } \\
\text { Cao Wei-Zhong (2014) }\end{array}$ \\
\hline Hebei Province & $\begin{array}{l}\text { Keeps close contact with colleges and universities to establish a } \\
\text { think tank alliance of colleges and Universities }\end{array}$ & He Jun (2016) \\
\hline Shanxi Province & $\begin{array}{l}\text { Expert team of building a compound science and technology } \\
\text { think tank }\end{array}$ & Zhang Yan-Yu (2019) \\
\hline Grand Bay District & $\begin{array}{l}\text { Innovation mechanism for collaborative development of } \\
\text { University think tanks }\end{array}$ & Yu Hui (2019) \\
\hline Shaanxi Province & Social science theory innovation think tank & Li Xue (2019) \\
\hline Heilongjiang provincial & Party management think tank model Guang-Hui (2019) & Li Zhao et al (2017) \\
\hline Shandong Province & $\begin{array}{l}\text { Improves the feedback mechanism and evaluation mechanism } \\
\text { of think tanks }\end{array}$ \\
\hline
\end{tabular}




\section{Think tank talent research}

The core of a think tank is talent, and talent is the key factor that determines the construction and development of a think tank. Qin Yan (2016) believes that in terms of the functions of think tank strategic research and decision making, both the production of knowledge and the transformation of knowledge results require the participation of think tank talents; Bao Zonghao's (1997) monograph "Decision Culture Theory" is based on modern decision culture. From a perspective, the importance of "using the external brain system" to modern leadership decision-making is analyzed, and this viewpoint also meets our requirements for the construction of think tank talent teams; Wang Danruo and Zhu Feng (2009) published "External Brain of Leaders "Contemporary Western Think Tank", a brief analysis of the background, classification, functions and activities of Western think tanks, and for the first time a comprehensive introduction to Rand Corporation and other famous American think tanks. The selection, training, management and use of think tank talents were introduced.

In general, the first is that most scholars have put forward some suggestions on the construction of think tanks from the development of the public decisionmaking consulting system, but there is still a gap with the actual construction of local think tanks, so they do not constitute a systematic empirical study of the countermeasures of local think tank construction issues. . Secondly, most of the choices of research subjects are mainly national think tanks and developed coastal areas. There is relatively little research on the development of think tanks that are underdeveloped and just starting, so it is impossible to talk about the construction of local think tanks under the guidance of scientific theory.

This study will refer to problems such as poor funding management systems, inadequate talent management, and inadequate incentive systems for think tanks during the construction of think tanks in other regions. Based on the actual situation of economic and political development in Pingxiang, China, a new type of construction suitable for the construction and development of Pingxiang Think tank model system.

\section{STATUS OF THE CONSTRUCTION OF NEW THINK TANKS AND THINK TANK TALENTS IN Pingxiang}

Pingxiang City started late in the construction of new-type think tanks. Pingxiang City does not currently have a relatively comprehensive large-scale think tank. Currently, think tanks include Sponge City Construction Think Tank, Luxi County Electric
Porcelain Industry Think Tank, Luxi County Agricultural Reform Demonstration Zone Think Tank, Pingxiang College E-Commerce Research Think Tank, etc. These think tanks are small in scale, have a single discipline, lack a sound scientific management system, cannot make full use of the talents in the think tank to make plans, and have relatively few scientific research results.

The establishment of a new type of think tank can not only rely on unilateral accumulation of outstanding talents, but also establish a comprehensive and scientific think tank management model. The current think tank management model of Pingxiang City is still at a relatively basic level, relying only on the introduction of outstanding talents to support the operation of the entire think tank. Pingxiang City should not only focus on the introduction of talents, but also the self-cultivation of talents and the retention of outstanding talents. In addition, Pingxiang City should build a comprehensive new think tank management system model from the six detailed perspectives of management mechanism, talent management, development environment, public communication, work mechanism, and excellence mechanism.

\section{NEW-TYPE THINK TANKS IN PINGXIANG CITY, CHINA SUPPORT INNOVATIVE MANAGEMENT APPROACHES}

According to the above analysis of the status of talent construction in Pingxiang, China, it can be concluded that Pingxiang City has a relatively complete and attractive talent introduction policy, but the gap in self-cultivation of talents is obvious. Secondly, Pingxiang City think tank is currently in In the initial stage, there is no new think tank structure with a complete system. In light of the advantages and disadvantages of talent construction in Pingxiang think tank and the current status of Pingxiang's political and economic development, Pingxiang should create a new type of think tank system and build a new type of think tank that can meet the requirements of urban innovation management. In this study, by studying the think tank system of other cities and combining with the actual situation of Pingxiang's political and economic development, a comprehensive new type of index with six elements of management mechanism, talent management, development environment, excellence mechanism, working mechanism and public communication has been established. Think tank model system, as shown in "Fig. 1".

It can be seen from the model in Figure 1 that the new think tank model system of Pingxiang City is centered on talents and consists of six elements, all of which are of vital importance to the establishment of a new think tank in Pingxiang City. 


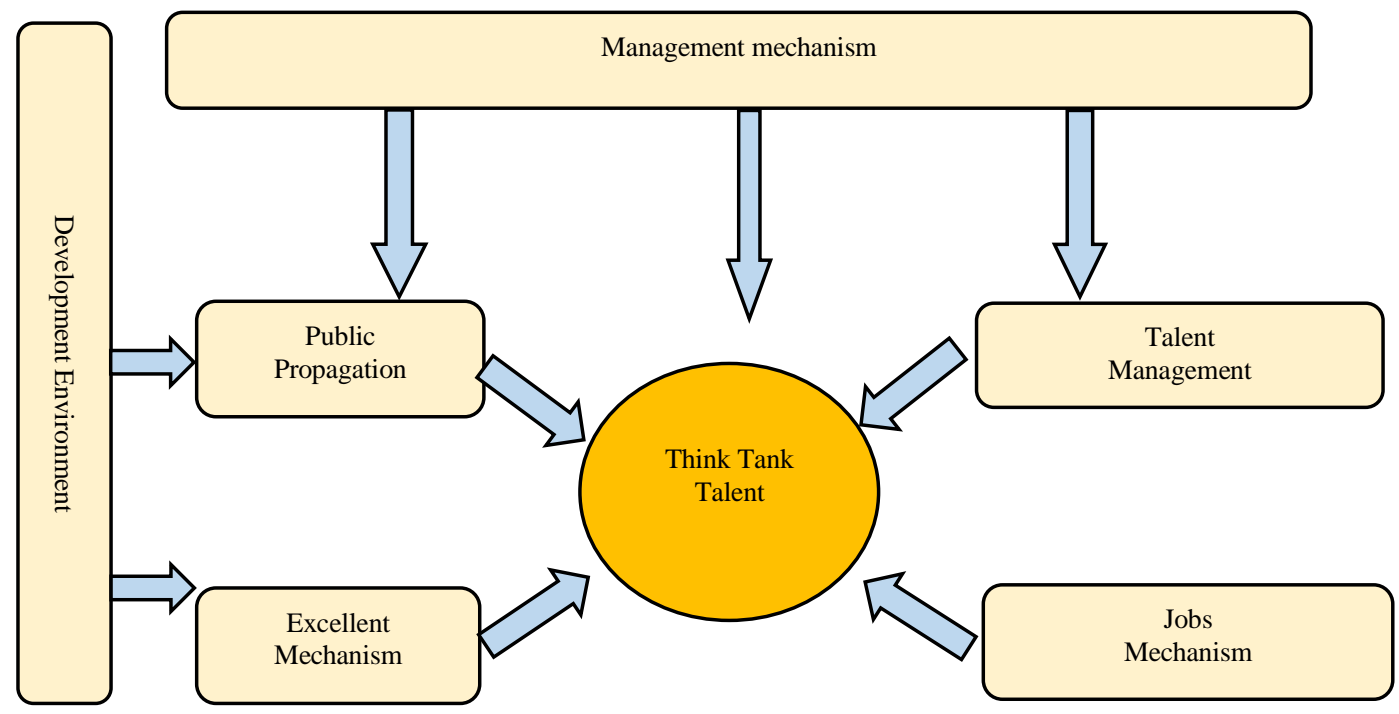

Fig. 1. A model system for the construction of a new think tank in Pingxiang, China.

\section{A. Management mechanism}

The management mechanism refers to the management mode of talents in the think tank. Whether a think tank can reasonably and effectively provide the local government with useful, accurate, and reliable information to help the government make decisions is closely related to the management mechanism of the think tank. A good management mechanism can maximize the efficiency of think tank talents, improve the efficiency of communication between talents in various disciplines, and bring together talents in various disciplines to overcome problems.

\section{B. Talent management}

Talent management refers to the management mode of talents in think tanks, which can be divided into two aspects: talent introduction and talent training. Although Pingxiang City has a good talent introduction policy, it is relatively backward in urban level and urban political and economic development. Therefore, Pingxiang city should expand its thinking, keep the original talent introduction policy unchanged, and focus on talent training. Form a three-dimensional talent management mechanism with the introduction of highend scientific research and technology talents as the main and self-cultivation as the auxiliary; the selfcultivation of high-end scientific research and technology talents as the main and introduction as the auxiliary.

Pingxiang city should strengthen personnel training from two aspects:

First, strengthen the training of existing think tanks. The level of talents in think tanks is uneven, and their scientific research capabilities are different. On the one hand, Pingxiang city should strengthen the further training of the existing talents of think tanks, and publicize the talent training system of "taking the strong with the weak, with the help of the master". On the other hand, it's necessary to encourage interdisciplinary exchanges among talents in think tanks and promote diversified development.

The second is to cooperate with local universities in Pingxiang City to explore new teaching mode and cultivate talents that meet the requirements of new think tanks in Pingxiang City. Pingxiang city should make use of Pingxiang University as a platform to actively carry out cooperation with Pingxiang University in talent cultivation, and make specific requirements on disciplines, quantity, mastery of specific knowledge and practical application level of talents required for the construction of new think tanks in Pingxiang City. This talent cultivation mechanism of "from the campus platform to the scientific research platform" is conducive to Pingxiang new think tanks to obtain excellent talents that are in line with the political and economic development of Pingxiang City and match with the development status of Pingxiang think tanks. It is conducive to the construction and development of new think tanks in Pingxiang City.

\section{Public communication}

Public communication refers to the use of various media to disseminate the academic views, policy guidelines and social influence of new think tanks. In today's era of rapid development of new media, new and old media blending and alternating, Pingxiang city should reasonably use new media and traditional media to carry out public communication. With the help of the characteristics of new media, such as timeliness, 
convenience, low cost, fast speed and wide range of communication, it's necessary to timely disseminate the new ideas of think tanks and interpret the introduction of new policies. Let the public have a more comprehensive understanding of the work content and quality of the new think tank, improve the social influence and credibility of the new think tank, which is conducive to the long-term development of the new think tank in Pingxiang City.

\section{Working mechanism}

The working mechanism emphasizes that Pingxiang new think tank should establish a scientific project selection mechanism, focus its work on all kinds of social hot issues that need to be solved urgently, and improve its own initiative service ability and efficient and high-quality problem-solving ability. Establish the tracking research mechanism of the key content, take the problem as the guidance, design the scientific and reasonable project to grasp the essence of the problem. Establish the supply mechanism of high-quality think tank achievements, put forward valuable suggestions to help the government make reasonable and accurate decisions, and establish a scientific, institutionalized, efficient, Trinity public decision-making around major issues such as the transformation of Pingxiang City's functions, the construction of new countryside, the reform of administrative approval system, the construction of sponge City, the government's performance management, and the reform of the city's enterprise innovation ability System, for Pingxiang city innovation management to make contributions.

\section{E. Mechanism of creating excellence}

The mechanism of creating excellence refers to the formation of an academic and scientific research atmosphere of "comparison and Surpassing" within the new think tanks of Pingxiang City. The salary level of every outstanding talents, experts and scholars in the think tank is related to their scientific research ability and the number of completed projects. We will encourage outstanding talents, experts and scholars in think tanks to keep learning and improve their scientific research and problem-solving abilities. It is conducive to the formation of an academic and scientific research atmosphere of "comparison and overtaking" and benign competition, so as to improve the comprehensive ability of think tanks to find, deal with and solve problems. Under the influence of the mechanism of creating excellence, it is conducive to forming a virtuous circle of attracting talents, reasonable competition and improving the influence of think tanks. It is also conducive to the further development of new think tanks in Pingxiang City and the improvement of decision-making ability and social influence.

\section{F. Development environment}

The development of Pingxiang new think tanks can not only rely on the official platform of the government, but also encourage the emergence and development of private think tanks, so that private think tanks and government think tanks complement each other, make common progress, and promote the development of Pingxiang new think tanks.

We will allow non-governmental think tanks to participate in the special report on public decisionmaking consultation, and establish a smooth channel for reporting the achievements of non-governmental think tanks to decision makers. With a good development environment, non-governmental think tanks are conducive to Pingxiang think tanks showing a "hundred schools of thought" attitude, rather than the government think tanks "one dominant". If talent is compared to water, think tanks are "reservoirs" of talent. The vigorous development of non-governmental think tanks can increase the number of "reservoirs" in Pingxiang City. The intensive exchange of non-governmental think tanks and government think tanks can effectively improve the development level of think tanks, and jointly contribute to the development of new think tanks in Pingxiang City.

\section{CONCLUSION}

In order to fully implement the opinions on strengthening the construction of new think tanks with Chinese characteristics issued by the general office of the CPC Central Committee and the general office of the State Council. Pingxiang city should make corresponding changes in response to the bottleneck of the current development of think tanks in Pingxiang City, with a view to breaking through the obstacles of the development of new think tanks in Pingxiang City and giving better play to the decision-making role of think tanks. This study will combine the Pingxiang new talent think tank system model, and put forward the following countermeasures and suggestions on the development of Pingxiang new talent think tank.

\section{A. Improving the management mechanism of think tanks and building a three-dimensional development model of think tanks}

In view of the current situation of the development of new think tanks in Pingxiang City, Pingxiang municipal government should formulate the overall plan for the construction of new think tanks in Pingxiang City, focusing on the development concept of "innovation, efficiency, sharing, cooperation, openness, environmental protection" and the major development strategies of "sponge City" and other regions, and from the overall perspective, improve the efficiency of resource allocation, improve the scientificity of think tank decision-making, and form an 
innovation and efficiency, a new type of think tank system of Pingxiang city with scientific layout, coordinated development, green environmental protection and local characteristics.

Pingxiang city should actively go to other cities in China for research, learn advanced talent management mechanism of think tanks, combine the actual situation of Pingxiang City, adjust measures to local conditions, make overall planning and layout, optimize the allocation of talent resources, and avoid repeated construction and disordered development. Actively promote the construction of Pingxiang Party school, Academy of Social Sciences, Academy of Sciences, "sponge city" and Pingxiang University and other comprehensive think tanks; accelerate the construction of think tanks for sustainable development and people's livelihood; vigorously cultivate local cultural think tanks and sharing and cooperation think tanks, so as to provide the development foundation for Pingxiang new think tank system.

\section{B. Improving the talent management and excellence creation mechanism of think tanks}

Pingxiang city should continue to maintain the existing "Pingxiang high-level talent introduction implementation measures", "Pingxiang City on deepening the reform of talent development system and mechanism action plan" and other talent introduction bonus policies. According to the current development situation of Pingxiang City and the specific situation of the required talents, the corresponding adjustment is made to the treatment of talents. This new talent evaluation system for think tanks is conducive to encouraging think tanks to actively participate in various government projects, strive to tackle difficult issues, improve the scientific nature of decisionmaking, and expand the influence of decision-making.

We will establish a new talent assessment and promotion mechanism for think tanks. The assessment and salary level of outstanding talents, experts and scholars in think tanks are linked to their scientific research ability, number of projects completed and decision-making influence. To improve the number of projects, decision-making influence and evaluation weight of research results in daily work performance, professional title evaluation and promotion of positions completed by think tank talents, so as to encourage excellent talents, experts and scholars in think tank to learn continuously and improve their own scientific research ability, which is conducive to promoting think tank to form a good academic research atmosphere of "comparison and overtaking".

\section{References}

[1] Wu Tianyou, Fu Xi. Think tank for Reagan (Continued) [J]. Modern international relations, 1982 (02): 62-64.

[2] Hu Angang. Building New Think Tanks with Chinese Features: Practice and Summary $[\mathrm{J}]$. The Journal of Shanghai Administration Institute, 2014,15 (02): 4-11.

[3] Zhu Xufeng. Perspective of the "Chinese brain" of foreign think tanks [J]. China report, 2009 (12): 49-51.

[4] Wang Lili, "revolving door": an important operation mechanism of American think tanks [N]. Learning times, 2012-11-05 (006).

[5] Ren Xiao. An objective view of the "other side" of American think tanks [N]. China Social Sciences Journal, August 27, 2015 (002).

[6] Quan heng. How to build a new pattern of Chinese think tanks under the new normal [N]. Guangming Daily, December 25, 2014 (015).

[7] $\mathrm{Xu} \mathrm{Xiaohu}$. Research on the components and competitiveness of local think tanks [D]. Nanjing University of Aeronautics and Astronautics, 2014.

[8] Cao Weizhong. Research on the construction of new think tanks in Jiangsu [D]. Nanjing University, 2014.

[9] He Jun. Research on Construction of Hebei Talent Think Tank - A Case Study of Local Universities [J]. Journal of Hebe University of Economics and Business(Comprehensive Edition), 2016, (3): 92-95.

[10] Zhang Yanyu. Exploration and Thinking on the Construction of Shanxi Science and Technology Think Tank [J]. Innovation Science and Technology, 2019, (6): 55-60.

[11] Yu Hui. Co-governance: Development Mechanism Innovation of Regional University Think Tanks in Guangdong-Hong KongMacao Greater Bay Area [J]. Journal of Soochow University(Educational Science Edition), 2019, (2): 20-28.

[12] Li Xue. Sticking to Innovation Leading to Promote Construction of High-Level Local Think-Tanks Continuously in the New Era - Interview with Bai Kuanli, Vice President of Shaanx Academy of Social Sciences [J]. China Economist, 2019, (10): 6-7.

[13] Zhang Guanghui. Research on the Sound Development Strategy of Local Social Think Tanks - Take Heilongjiang Province as an Example [J]. Think Tank:Theory \& Practice, 2019, (3): 48$55+64$.

[14] Li Zhao, Li Haibo, Ma Yu, Ru Xuwei, Chen Na. Problems and Countermeasures of Local Think Tanks Serving Scientific Decision Making - Taking Shandong Province as an Example [J]. Think Tank:Theory \& Practice, 2017, (3): 80-85.

[15] Qin Yan. Talent cultivation of think tanks in foreign universities [D]. East China Normal University, 2016. 